\title{
Capítulo

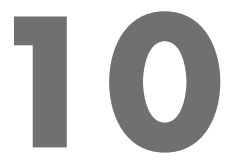

\section{ANÁLISE DO PROCESSO DE COMUNICAÇÃO DOS ALIMENTOS FUNCIONAIS: UM ESTUDO DAS EMBALAGENS DE PÃES DE FÔRMA}

\author{
Suellen Santos Kikuchi Ribeiro \\ João Cairo Ferreira \\ Marco Antônio Ferreira
}

\section{INTRODUÇ̃̃O}

O pão está entre os alimentos que mais prevalece na construção da dieta do brasileiro, com alto consumo diário e em proporções próximas entre o público masculino e feminino, além de ser acessível para diferentes rendas familiares. O consumo de pão dentro dos domicílios do Brasil pode chegar a até $6 \%$ da quantidade de caloria total da alimentação familiar (SOUZA et al., 2013).

As tendências de consumo dos brasileiros têm passado por um processo de mudança ao longo dos últimos anos, principalmente em relação à alimentação. Os consumidores buscam por variedades e inovações no setor alimentício, mostrando uma postura mais crítica e exigente à criação de novos produtos. Fatores como a individualidade, o ambiente e as alterações emocionais de cada indivíduo devem ser levados em consideração na análise de tendência de consumo de cada grupo de consumidores (GOULART; CHEUNG, 2014).

Parte da mudança na produção de alimentos vem surgindo para acomodar as necessidades do público mais sensível às questões sustentáveis. A publicação da ONU referente ao desperdício mundial de alimentos e a sua relação com o cenário brasileiro têm levado parte da população a se engajar em uma campa- 
nha solidária à economia de recursos naturais. A escolha de locais para realizar as refeições é um fator muito importante no país. Segundo Agrocluster (2015), estatísticas apontam que entre os brasileiros que escolhem realizar refeições fora de seus domicílios, cerca de $40 \%$ optam por um atendimento especializado em restaurantes à la carte e/ou em padarias.

A distribuição da renda é outro fator que influencia diretamente nas decisões alimentares no Brasil, pois apenas uma pequena parcela de cidadãos considerados como mais ricos retém cerca de $30 \%$ do rendimento do país, o que indica que o poder de compra de grande parte da população é um fator essencial para traçar o perfil de consumo (AGROCLUSTER, 2015).

Surge então uma nova linha de produção alimentícia, com o intuito de atrair consumidores que buscam produtos e serviços diferenciados, fenômeno denominado "gourmetização" (FERREIRA; VALDUGA; BAHL, 2016). Segundo Sebrae/ABIP (2009), essa tendência de produção e consumo busca atender as necessidades de singularidade dos consumidores, que procuram produtos diferentes, que fogem do padrão, e que os façam ganhar status e qualidade de vida.

Para acompanhar o desenvolvimento das novas tecnologias do setor alimentício e atender as demandas das novas tendências de consumo, o setor de panificação passa então a reformular seus espaços físicos e os produtos disponibilizados ao consumidor. Esse crescimento mostra um investimento e uma mudança notável quanto à forma de comercialização e produção desde 2009, período em que cerca de $80 \%$ dos estabelecimentos de panificação levaram o título de padarias artesanais, tendo como foco a produção própria e personalizada para consumidores da região em que estavam alocadas, tentando atingir um público maior e mais versátil (SEBRAE/ABIP, 2009).

A importância do pão na cultura brasileira e as alterações sofridas no setor da panificação nos últimos anos são fatores essenciais na análise de mercado e de tendências desse ramo. Devido a isso, é importante avaliar e conhecer os consumidores, os estabelecimentos de panificação e suas rotinas, para que com esses dados seja possível, futuramente, criar um plano estratégico para a melhoria dos processos de desenvolvimento de novos produtos, de produção e divulgação de alimentos de diferentes panificadoras, confeitarias e indústrias com foco em nichos específicos de consumidores.

Um estudo feito entre os anos de 2008 e 2009 mostra que o consumo de pão de sal entre homens e mulheres acima de 10 anos de idade foi de $63 \%$, o que evidencia que ele está entre os alimentos mais consumidos entre o público brasileiro, juntamente com o arroz, o café e o feijão, e de forma homogênea em 
todo território, não havendo uma região em que ele prevaleça em comparação as outras (SOUZA et al., 2013).

As mudanças de hábitos de consumo estão cada vez mais presentes, principalmente entre as faixas etárias mais novas. No mesmo estudo, foi verificado que adolescentes não incluíram nenhuma hortaliça em sua dieta básica e citaram o consumo de doces, biscoitos e bebidas lácteas, o que pode acarretar na redução de consumo de pães, uma vez que esses jovens são os futuros adultos e responsáveis pelas compras de alimentos em suas residências (SOUZA et al., 2013).

Apesar de o pão estar entre os alimentos mais consumidos, essa categoria alimentícia da dieta básica dos brasileiros (categoria em que o pão se encaixa) estão tendo o seu consumo reduzido, como o arroz, por exemplo. Dados recolhidos entre 1974 e 2003 mostram que o consumo per capita desses alimentos foram reduzidos, como por exemplo o arroz, que passou de aproximadamente $31 \mathrm{~kg}$ per capita para 17kg (COELHO; AGUIAR; FERNANDES, 2009).

Enquanto o consumo de alimentos da dieta tradicional brasileira vem diminuindo ao longo dos anos, o de frutas e alimentos preparados vem aumentando, devido ao nível de escolaridade dos brasileiros ter melhorado, ao acesso às informações em relação às necessidades nutritivas de cada faixa etária e às mudanças de estrutura das famílias, pois a mulher passa a trabalhar fora de casa e a procurar alimentos mais práticos e rápidos de consumir (COELHO; AGUIAR; FERNANDES, 2009).

Acredita-se que com o passar dos anos a produção de pães venha tentando adapta-se às alterações de comportamento e necessidades dos consumidores, modificando a evolução e a criação de novos produtos, para atender as demandas desse público cada vez mais exigente e para acompanhar as novas tendências de produtos com apelo mais nutritivo e saudável.

O objetivo deste trabalho foi analisar o processo de comunicação a um nicho de consumidores que buscam alimentos saudáveis e realizar um estudo de sobre pães de fôrma funcionais.

\section{CONTEXTUALIZAÇÃO SOBRE ALIMENTOS FUNCIONAIS, TENDÊNCIAS DE CONSUMO E CARACTERÍSTICAS MERCADOLÓGICAS INERENTES AO PÃO}

A produção e o consumo de pães ao longo da história difundiu-se e diferenciou-se através das diversas religiões, culturas e filosofias quanto às decisões de investimentos e melhorias das tecnologias na produção alimentícia. 
Sabendo-se da importância desse alimento ao redor do mundo, torna-se necessária a análise das particularidades dos consumidores, como também a verificação, por meio da história do pão e de suas mudanças ao longo dos anos, de quais foram as melhorias feitas em seu processo de produção, divulgação e comercialização a fim de atender ao público que busca alimentos mais saudáveis.

\subsection{O PÃO, SUA HISTÓRIA E CONTEXTO MUNDIAL}

Não é possível determinar precisamente a história do pão, assim como a cronologia e a evolução dos costumes e estilo de vida humano, porém, estima-se que esse alimento faça parte da dieta humana por pelo menos 500 mil anos. Há indícios de seu consumo em diversos países e regiões (BRAGA, 2006).

Segundo Jacob (1944), os egípcios foram um dos primeiros povos a utilizar o conceito de forno para preparar suas refeições e, a partir disso, surgiram os modelos mais tradicionais de pão conhecidos ao redor do mundo. O mesmo autor conta como os registros históricos apontam que os gregos foram os pioneiros em padarias artesanais artísticas, fazendo com que eles sejam considerados os melhores produtores de pão da antiguidade ocidental.

$\mathrm{Na}$ atualidade, o Brasil, quando comparado a outros países da América Latina, tem um consumo de pão abaixo da média. O consumo desse alimento em 2004 foi em torno de $28 \mathrm{~kg}$ per capita, enquanto a Organização Mundial da Saúde (OMS) e a Organização das Nações Unidas (ONU) propõem, respectivamente, que o consumo desse alimento seja de pelo menos $60 \mathrm{~kg}$ e $50 \mathrm{~kg}$ por ano (PIRES et al., 2009).

De acordo com um levantamento do Sebrae publicado em 2000, o setor da panificação na década de 90 ocupava uma fração importante da economia brasileira, gerando empregos, faturando bilhões e chegando a quase $8 \%$ do total produzido pelo setor alimentício (SEBRAE, 2000).

Dados mais recentes da Associação Brasileira da Indústria de Panificação e Confeitaria (ABIP) apontam que a panificação continua tendo um importante lugar na economia brasileira, representando ainda $7 \%$ do total de faturamento por indústrias, e receita de cerca de 70 bilhões, que significam quase $2 \%$ do PIB (ABIP, 2012).

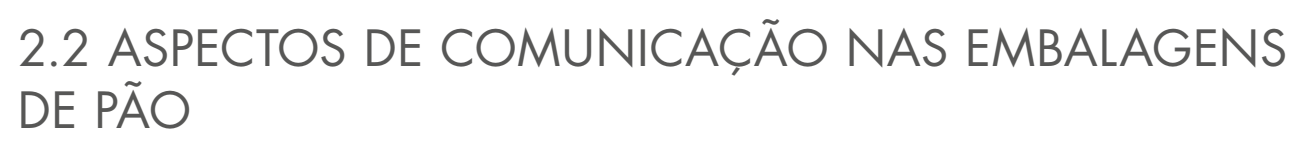

A embalagem de um produto é um dos fatores mais importantes em sua divulgação e apresentação para o público, podendo ser o elemento decisivo para 
o consumidor na hora da compra. Segundo Kotler (1995), a embalagem é uma grande ferramenta de marketing principalmente pelos seguintes fatores: o aumento do número de produtos vendidos sem vendedor, o reconhecimento do setor de vendas em relação à importância do desenho da embalagem, os benefícios que uma embalagem inovadora traz para os consumidores e a aceitabilidade do cliente em pagar a mais por produtos com maior conveniência e que aparentemente demonstrem mais confiabilidade e prestígio.

Oficialmente, a legislação vigente da Anvisa (2005) determina que as embalagens e a rotulagem de pães devem ser seguras para não oferecer nenhum risco a saúde do consumidor e proíbe a utilização de termos e frases que associem os produtos a cura de doenças e tratamentos terapêuticos. A legislação ainda exige que pães tenham a rotulagem nutricional (Quadro 1) adicionada na embalagem do produto e ainda orienta o consumidor a verificar tais informações e como utilizá-la (ANVISA, 2008). Devido à pequena quantidade de restrições previstas na legislação para esse pães, as empresas acabam tendo grande liberdade na hora de produzir as embalagens e imagens atreladas à venda desse tipo de alimento .

Por outro lado, analisando-se os métodos de criação de valor do produto do ponto de vista do comprador, há aspectos como estilo, design, embalagem e rótulo que precisam ultrapassar as informações básica exigidas para o produto. Sendo assim, a aparência, o molde, a exclusividade da embalagem, as informações do local de produção, conteúdo e formas de consumo do alimento que se está adquirindo tornam-se fatores essenciais na conquista do consumidor (KOTLER; ARMSTRONG, 2007).

Quadro 1 - Rotulagem Nutricional de Pão de Forma Tradicional

\begin{tabular}{|l|c|c|}
\hline \multicolumn{3}{|c|}{ PÃO DE FORMA TRADICIONAL } \\
\hline & $\begin{array}{c}\text { Quantidade por porção } \\
\text { (5 g por parte comestível) }\end{array}$ & \%VD(*) \\
\hline Valor Energético & $529 \mathrm{kj}$ & 6,5 \\
\hline Carboidratos & $22 \mathrm{~g}$ & 7,5 \\
\hline Proteínas & $6 \mathrm{~g}$ & 8 \\
\hline Gorduras Totais & $1 \mathrm{~g}$ & 2 \\
\hline Gorduras Saturadas & $0,2 \mathrm{~g}$ & 1 \\
\hline Gordura Trans & $0,1 \mathrm{~g}$ & 5 \\
\hline Fibra Alimentar & 1,2 & 0,5 \\
\hline Sódio & $11 \mathrm{mg}$ & VD não estabelecido \\
\hline
\end{tabular}

(*) \% Valores Diários de referência com base em uma dieta $2.000 \mathrm{kcal}$ ou $8.400 \mathrm{kj}$. Os valores diários podem ser maiores ou menores dependendo das diferentes necessidades energéticas.

Fonte: Tabela TACO (NEPA, 2011). 
Atualmente existem diversas marcas de pães nacionais e regionais, o que acaba estimulando ainda mais as empresas a desenvolverem embalagens que chamem mais a atenção do consumidor, transmitam os valores que o público procura e os façam criar laços com a marca e indicar para as pessoas que conhece. Segundo Kotler (1993), os fatores sociais associados a compra de produtos são grupos de referência como família, amigos, vizinhos e pessoas consideradas importantes na sociedade, de forma que seus gostos e escolhas afetam de maneira direta e indireta o comportamento e decisão de compra das pessoas.

Para o desenvolvimento de embalagens, leva-se em consideração que estas estão diretamente ligadas à decisão de compra, e aplicam-se conhecimentos de design, como a escala de cores, que podem influenciar no sentimento do consumidor. Por exemplo, para que seja estabelecido parte do relacionamento inicial com o consumidor, muitas empresas utilizam cores quentes (vermelho, laranja, parte do amarelo e do roxo) para as embalagens de pães das linhas tradicionais, pois essas cores podem trazer sensação de proximidade, densidade, calor e estímulo (FARINA; PEREZ; BASTOS, 2006).

Quadro 2 - Cores utilizadas nas embalagens de pão de fôrma tradicional analisadas no trabalho (2017)

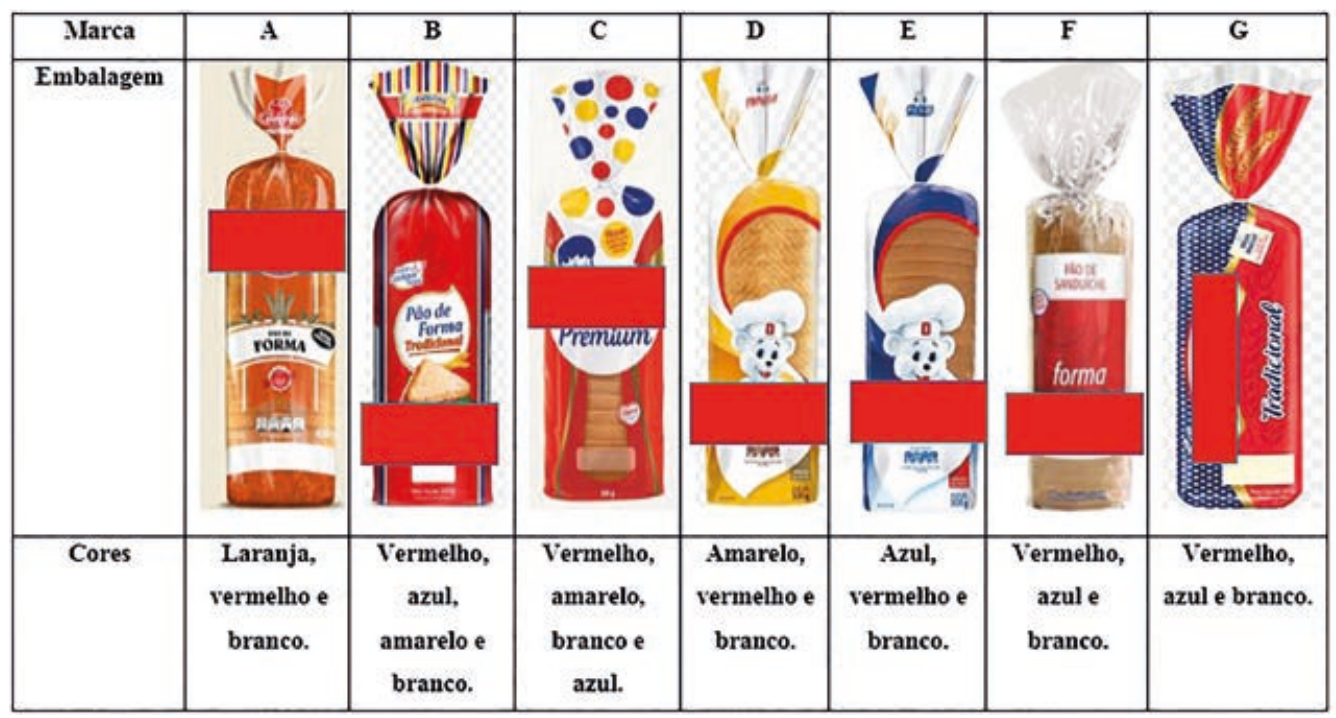

Fonte: Autoria Própria (2017).

Já as cores frias (azul, verde, parte do amarelo e roxo), que normalmente são associadas a sensação de distância e transparência, também podem ser relacionadas a calma e leveza (FARINA; PEREZ; BASTOS, 2006). Muitas 
marcas brasileiras de pães utilizam essas cores para os produtos integrais ou com ingredientes que tragam benefícios adicionais para o organismo (Quadro 3), para que seus produtos passem a sensação de leveza.

Dessa forma, pode-se verificar que as embalagens, além de fornecerem as informações obrigatórias sobre o produto, de acordo com a legislação vigente, também são o veículo de comunicação da empresa com o consumidor e a imagem que ela deseja passar sobre valores e qualidade dos seus produtos.

Quadro 3 - Cores utilizadas nas embalagens de pão de fôrma integral

\begin{tabular}{|c|c|c|c|c|c|c|c|}
\hline Marca & A & B & C & D & E & F & G \\
\hline Embalagem & & & & & \\
& & &
\end{tabular}

Fonte: Autoria Própria (2017).

Ainda que as embalagens sejam, na maior parte do tempo, o principal veículo de comunicação entre a empresa e o consumidor, muitos produtos inovadores ainda acabam por deixar de ser mais bem conhecidos por não passarem por completo a mensagem que justifique sua compra em detrimento de outro produto a que o consumidor já está habituado, um exemplo disso ocorre com o pão funcional. No Brasil, até hoje só houve uma marca de pães disposta a produzir um pão funcional, porém, a embalagem desse produto somente transmitia informações como "Maxi Fibra" e imagens que relacionavam seu consumo ao bem-estar e melhor funcionamento do intestino (Figura 1). 
Figura 1 - Pão funcional e informações contidas na embalagem

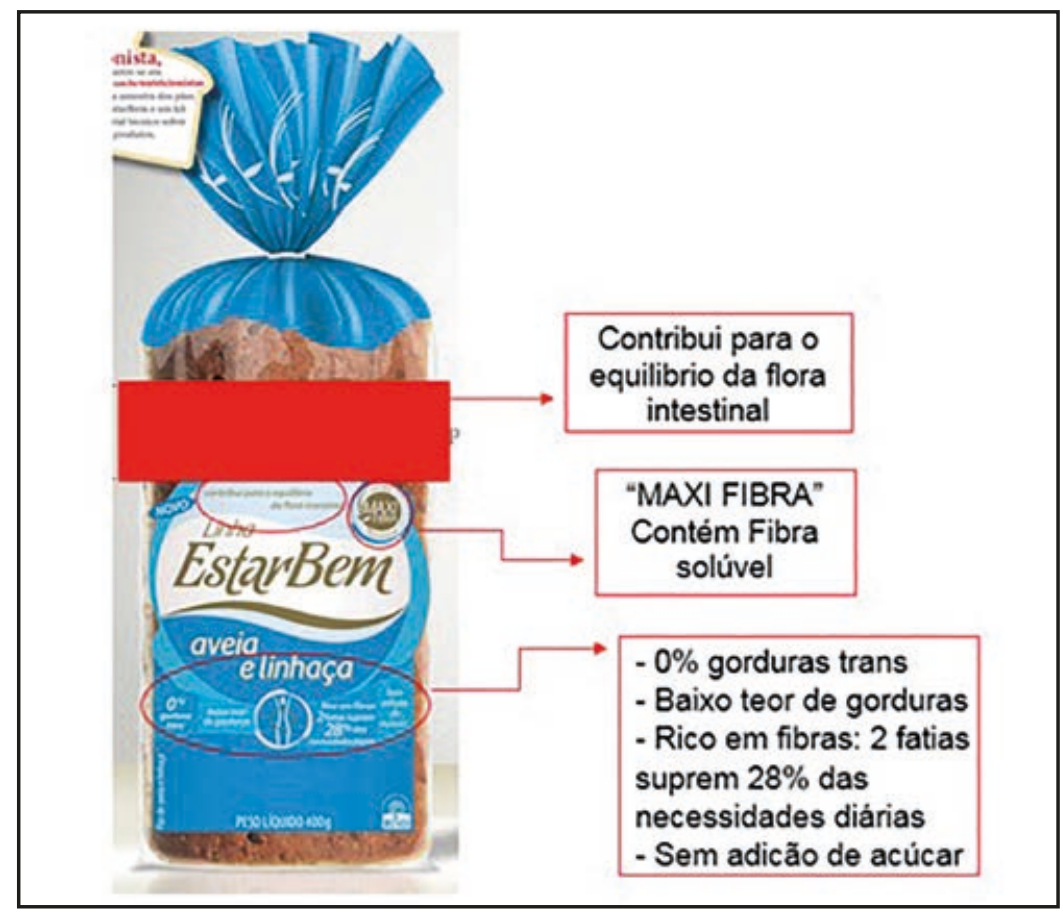

Fonte: Autoria Própria (2017).

\subsection{TENDÊNCIAS DE CONSUMO}

Internacionalmente acontecem com frequência análises de tendências de consumo em diversos setores que oferecem serviços e produtos, para identificar as preferências e necessidades dos consumidores. Devido a constante preocupação em atender as necessidades e desejos dos clientes da melhor maneira possível, a área de alimentos analisa e divide as tendências de consumo em cinco principais grupos. Os relatórios estratégicos na área de alimentos apontam que esses grupos são: Sensorialidade e Prazer; Saudabilidade e Bem-estar; Conveniência e Praticidade; Confiabilidade e Qualidade; e Sustentabilidade e Ética (BARBOSA et al., 2010).

O perfil do consumidor brasileiro, não se encaixa diretamente em todas essas classificações. Segundo pesquisa do Ibope (2010), o brasileiro tem tendências de consumo que se assemelham com três das cinco categorias globais, que relacionam o prazer, a fidelidade às marcas e a conveniência dos produtos, sendo os fatores que mais influenciam na decisão de compra: o preço, a marca de confiança e a saudabilidade do produto. 
O aumento ou declínio populacional, a taxa de natalidade, a colocação da mulher no mercado de trabalho, as condições financeiras, a escolaridade e a migração do campo para o meio urbano são traços da sociedade brasileira que ao longo das últimas décadas vêm se acentuado e continuarão a aumentar a influência nas escolhas dos consumidores. Fatores como o trabalho, a renda, o espaço e o tempo a serem gastos em uma refeição se tornam então pontos focais nas decisões de compra do brasileiro (COSTA; MACÊDO; HOCZAR, 2010).

- Sensorialidade e Prazer: esta categoria de produtos está diretamente ligada às emoções do consumidor em relação ao alimento. Segundo Barbosa et al. (2010), há nesta classe uma retenção maior de informação e educação, fazendo com que se exijam produtos de maior qualidade, e culinária que proporcione novas experiências e oportunidades.

- Saudabilidade e Bem-estar: já os produtos que focam a saudabilidade e bem-estar, buscam atingir o público que se preocupa com a saúde e com a melhor qualidade de vida. As doenças do novo século foram fatores decisivos para a criação deste novo grupo de consumidores que se preocupam com a prevenção e remediação de doenças que podem ser amenizadas com uma alimentação regrada. Marcas de supermercados mundialmente bem difundidas tem investido em produtos relacionados ao bem-estar e saúde, a fim de aproveitar o crescimento do interesse dos consumidores em produtos benéficos para o corpo (EXAME, 2015).

- Conveniência e Praticidade: este grupo busca atender os consumidores que ao longo dos anos são afetados pelo ritmo de vida acelerado e uma rotina cheia de atividades. Para auxiliar os consumidores com este perfil, as indústrias e restaurantes buscam criar produtos com tamanhos e quantidades menores, para consumo rápido e fora de casa (BARBOSA et al., 2010).

- Confiabilidade e Qualidade: o avanço tecnológico e o alcance rápido à informação têm permitido que os consumidores se tornem mais informados e atentos em relação aos produtos oferecidos nas diversas áreas de consumo. No setor alimentício, o acúmulo de informações faz com que o consumidor busque alimentos com maior qualidade, com certificações e garantia de origem (BARBOSA et al., 2010). Esta categoria de produtos está diretamente relacionada à aderência dos consumidores a marcas específicas.

- Sustentabilidade e Ética: segundo Bortolon e Mendes (2014), o ser humano passou a transformar o foco da sustentabilidade para algo pessoal, para satisfazer suas vontades, sem comprometer os recursos e capacidades 
futuras. Partindo dessa ideia, surge a tendência de consumo que abrange a sustentabilidade e ética, onde os consumidores buscam produtos que gerem pouco impacto ambiental e que possam, de alguma maneira, ajudar pequenas empresas e famílias que se sustentam da produção agrícola e artesanal.

\subsection{ALIMENTOS FUNCIONAIS E ESCOLHAS SAUDÁVEIS}

O termo alimento funcional surgiu no Japão na década de 1980, porém, atualmente não existe nenhuma definição que seja aceita internacionalmente de forma homogênea, sendo que a mais aceita é a que os descreve como alimentos que trazem benefícios que vão além das funções básicas ao organismo, levando à prevenção de doenças e, de alguma forma, à melhoria da saúde e bem-estar (DIPLOCK et al., 1999).

A denominação de alimento funcional cabe ainda a alimentos naturais, em que algum componente tenha sido removido, a alimentos em que a biodisponibilidade de um ou mais componentes haja sido alterada, a alimentos em que algum composto tenha sido adicionado e ainda àqueles cuja a natureza de um ou mais componentes possa ter sido alterada, sempre levando-se em consideração que o funcionamento de cada alimento em cada organismo vai depender de suas diferenças genéticas, e que o alimento considerado funcional poderá não ter os mesmos efeitos para todos os indivíduos da população (KOK,1999).

A legislação brasileira proíbe a utilização da alegação de propriedade funcional quando ligada à cura ou prevenção de doenças (ANVISA, 2017). A Anvisa (2017) regulamenta a utilização do termo de alimento funcional, que somente é permitida quando for comprovada a existência dos ingredientes e substâncias bioativas e probióticos registrados junto ao órgão competente, e a propaganda não pode ser feita de forma diferente em qualquer maneira de seu significado que já é previamente aprovado para rotulagem.

Para que as marcas possam chamar a atenção do consumidor para os benefícios dos produtos funcionais, muitas colocam frases em relação à composição nutricional diferenciada na frente da embalagem. Mesmo que algumas marcas não apresentem grandes modificações na rotulagem nutricional entre o pão tradicional e a linha funcional (Quadro 4), o produto funcional normalmente é anunciado como alimento com diversos benefícios para o funcionamento do organismo e mais rico em nutrientes do que os demais produtos.

Apesar das restrições de rotulagem e denominação, os alimentos funcionais estão se tornando cada vez mais visíveis dentro do setor alimentício, não só 
por conta de seus benefícios para organismo, como também devido ao plano de fortalecimento da distribuição de informações sobre alimentação saudável da Organização Mundial de Saúde (WHO, 2004) e ao investimento em marketing, propaganda e publicidade de alimentos funcionais que as empresas têm explorando cada vez mais.

Quadro 4 - Comparação da Rotulagem Nutricional de Pão de Fôrma Tradicional e Pão de Fôrma Funcional com Maxi Fibra (Inulina) marca X

\begin{tabular}{|l|c|c|c|c|}
\hline & \multicolumn{2}{|c|}{$\begin{array}{c}\text { PÃO DE FORMA } \\
\text { TRADICIONAL }\end{array}$} & \multicolumn{2}{c|}{$\begin{array}{c}\text { PÃO DE FORMA } \\
\text { FUNCIONAL }\end{array}$} \\
\hline & $\begin{array}{c}\text { Quantidade por } \\
\text { porção (50 g por } \\
\text { parte comestível) }\end{array}$ & \%VD(*) & $\begin{array}{c}\text { Quantidade por } \\
\text { porção (50 g por } \\
\text { parte comestível) }\end{array}$ & \%VD(*) \\
\hline Valor Energético & $529 \mathrm{kj}$ & 6,5 & $506 \mathrm{kj}$ & 6 \\
\hline Carboidratos & $22 \mathrm{~g}$ & 7,5 & $20 \mathrm{~g}$ & 7 \\
\hline Proteínas & $6 \mathrm{~g}$ & 8 & $5,5 \mathrm{~g}$ & 7 \\
\hline Gorduras Totais & $1 \mathrm{~g}$ & 2 & $1,4 \mathrm{~g}$ & 3 \\
\hline $\begin{array}{l}\text { Gorduras } \\
\text { Saturadas }\end{array}$ & $0,2 \mathrm{~g}$ & 1 & $0,6 \mathrm{~g}$ & 3 \\
\hline Gordura Trans & $0,1 \mathrm{~g}$ & $* *$ & $0 \mathrm{~g}$ & $* *$ \\
\hline Fibra Alimentar & $1,5 \mathrm{~g}$ & 5 & $7 \mathrm{~g}$ & 28 \\
\hline Inulina & $0 \mathrm{~g}$ & $* *$ & $4,4 \mathrm{~g}$ & $* *$ \\
\hline Sódio & $11 \mathrm{mg}$ & 0,5 & $255 \mathrm{mg}$ & 11 \\
\hline
\end{tabular}

(*) \% Valores Diários de referência com base em uma dieta 2.000 kcal ou $8.400 \mathrm{kj}$. Os valores diários podem ser maiores ou menores dependendo das diferentes necessidades energéticas. (**) Valores Diários não estabelecido.

Fonte: Tabela TACO (NEPA, 2011).

Empresas como Nestlé e Danone investem em produtos funcionais desde 1990 no mercado exterior e atualmente têm buscado renovar as linhas de produtos lácteos dentro do mercado brasileiro, a fim de difundir a ideia da funcionalidade dos probióticos para o organismo (RAUD, 2008). Investimentos como este estão se tornando mais comuns por conta do aumento de $50 \%$ desse nicho entre os anos de 2002 e 2005, e por ser um setor muito lucrativo (SOCIEDADE BRASILEIRA DE ALIMENTOS FUNCIONAIS, 2017).

Haja vista a nova necessidade dos consumidores, as empresas do setor de panificação têm se adequado para atender o público através do investimento em marketing de relacionamento, onde se tenta extrair o melhor proveito da empresa 
e conscientizar todos os colaboradores, para que a busca pelo o sucesso da companhia e a satisfação do cliente sejam ideias intrínsecas no dia a dia empresarial (MACHADO et. al, 2012).

\section{MATERIAIS E MÉTODOS}

Tratou-se de um estudo descritivo que, segundo Andrade (2006), tem a função de transcrever dados encontrados em unidades de análise. $\mathrm{O}$ estudo contou com uma pesquisa qualitativa e bibliográfica. As pesquisas qualitativas e descritivas foram realizadas após as pesquisas bibliográficas.

As abordagens foram feitas com dez consumidores em potencial por meio de entrevistas não estruturadas, gravadas com o auxílio de um smartphone, com perguntas objetivas e subjetivas, ao longo ano de 2017, na cidade de Londrina, no Paraná. Os entrevistados foram selecionados de acordo com seu perfil de vida, idade (acima de 25), a fim de selecionar pessoas que realizassem as próprias compras de alimentos, tivessem hábitos alimentares previamente observados e disponibilidade de tempo para a realização do estudo. O tempo médio de cada entrevista foi de 12 minutos para que todos os aspectos do roteiro, ou aqueles que se apresentaram pertinentes a cada entrevistado, fossem abordados.

A unidade de análise desta pesquisa foram os consumidores, seus hábitos de consumo, e a forma de apresentação e exposição dos produtos consumidos por eles, além dos aspectos de marketing envolvidos na venda e divulgação desses produtos. Também foi feita a comparação entre consumidores que apresentavam características de consumo divergentes das dos pesquisados.

Tabela 1 - Características dos entrevistados

\begin{tabular}{lcccccccccc}
\hline \multirow{2}{*}{ Característica } & $\begin{array}{c}\text { Suj. } \\
\text { A }\end{array}$ & $\begin{array}{c}\text { Suj. } \\
\text { B }\end{array}$ & $\begin{array}{c}\text { Suj. } \\
\text { C }\end{array}$ & $\begin{array}{c}\text { Suj. } \\
\text { D }\end{array}$ & $\begin{array}{c}\text { Suj. } \\
\text { E }\end{array}$ & $\begin{array}{c}\text { Suj. } \\
\text { F }\end{array}$ & $\begin{array}{c}\text { Suj. } \\
\text { G }\end{array}$ & $\begin{array}{c}\text { Suj. } \\
\text { H }\end{array}$ & $\begin{array}{c}\text { Suj. } \\
\text { I }\end{array}$ & $\begin{array}{c}\text { Suj. } \\
\text { J }\end{array}$ \\
\hline Sexo & M & M & M & F & F & M & M & M & M & M \\
Idade & 26 & 25 & 56 & 25 & 51 & 30 & 45 & 30 & 32 & 26 \\
Perfil & PS & PS & S & NS & S & S & NS & S & PS & S \\
Duração $(\min )$ & 15 & 14 & 10 & 12 & 11 & 10 & 8 & 9 & 10 & 12 \\
\hline
\end{tabular}

Notas: PS - Pouco Saudável, S - Saudável e NS - Não Saudável Fonte: Autoria Própria (2017).

Para tanto, o trabalho foi dividido em duas principais etapas, sendo elas:

- Pesquisa qualitativa e descritiva do comportamento de consumo do nicho estudado, por meio de uma entrevista não estruturada feita pessoalmente 
com os consumidores, utilizando um roteiro de tópicos a serem abordados, descritos a seguir:

- Identificar quais são os hábitos alimentares.

- Identificar a rotina de exercícios físicos praticados.

- Identificar a frequência do consumo de pães.

- Identificar os fatores que influenciam de forma primordial a decisão de compra de produtos de forma geral.

- Identificar o grau de interesse por produtos saudáveis.

- Apresentar três produtos denominados como A, B e C, da mesma marca $\mathrm{X}$ (não identificada, para que não influencie os resultados da pesquisa), das linhas Funcional, Tradicional e Integral, respectivamente, e identificar qual a intenção de compra analisando somente a embalagem.

- Identificar se a rotulagem nutricional e os ingredientes dos produtos apresentados influenciam na decisão de compra.

- Identificar se o preço dos produtos influencia na decisão de compra.

- Identificar o conhecimento sobre o que o termo "alimento funcional" significa.

- Identificar se há conhecimento em relação às diferenças entre um pão funcional e um produto integral.

- Identificar quais são as informações que mais influenciam na decisão de compra no primeiro contato com um produto novo.

- Análise qualitativa e descritiva dos dados das transcrições das entrevistas por meio da comparação dos resultados por método de correlação.

\section{RESULTADOS E DISCUSSÃO}

Neste estudo foram analisados os hábitos alimentares, as tendências de consumo de alimentos e a intenção de compra de pães denominados "saudáveis" de dez consumidores. Entre os entrevistados, houve a possibilidade de comparar as tendências de consumo de um público que busca alimentos mais saudáveis com outros públicos que costumam priorizar fatores distintos na sua decisão de compra de alimentos, principalmente o pão.

Levando-se em consideração os resultados da pesquisa feita pelo Ibope em 2010, os resultados deste estudo puderam enfatizar que o perfil de consumo de 
alimentos dos brasileiros se limita, de forma geral, aos aspectos relacionados ao prazer, fidelidade à marca e conveniência dos produtos (IBOPE, 2010). Os entrevistados citaram principalmente a marca, saudabilidade e conveniência da embalagem como requisitos para suas decisões de compras, como está representado no Gráfico 1.

\section{Gráfico 1 - Fatores que influenciam a decisão de compra}

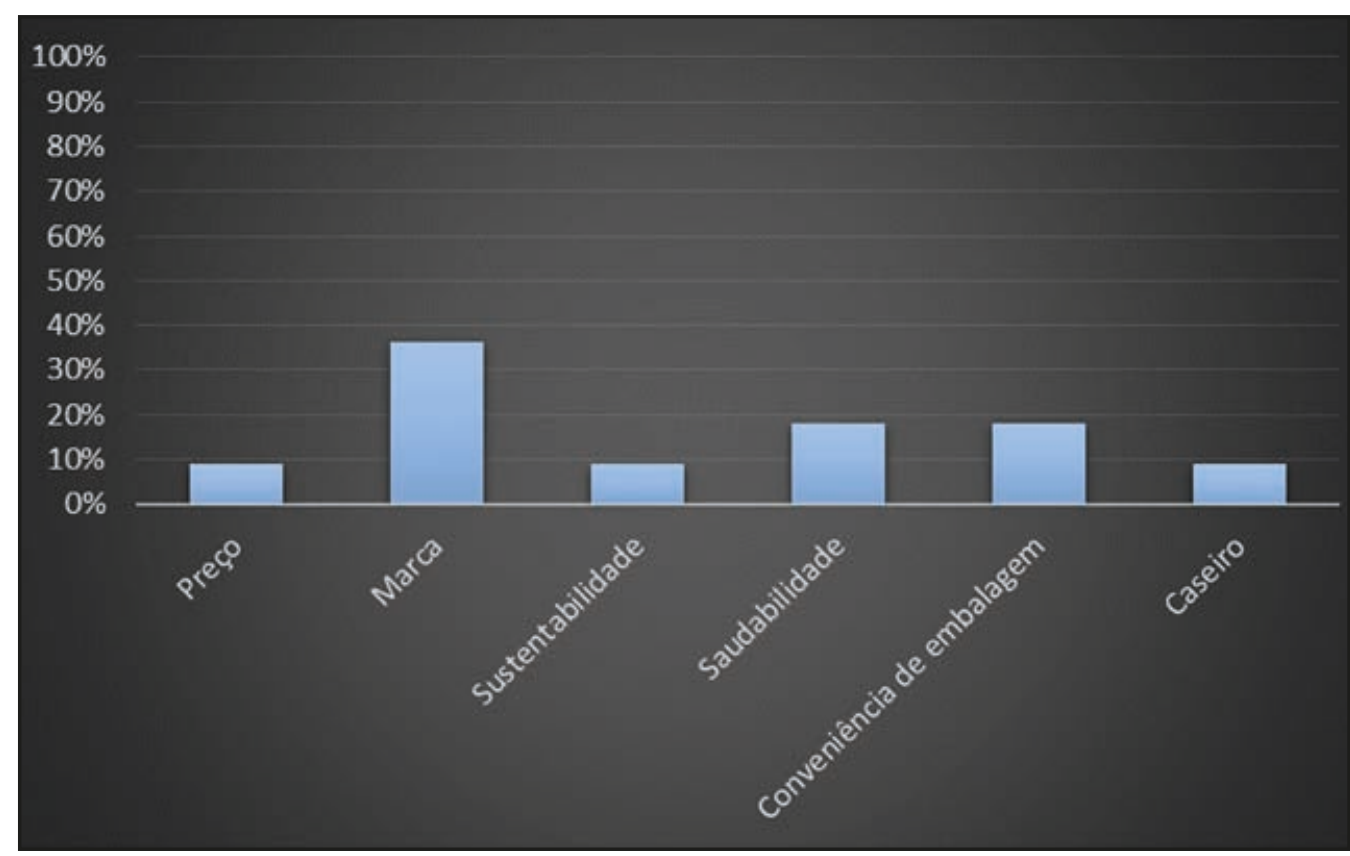

Fonte: Autoria Própria (2017).

Em relação à embalagem e ao marketing empregado nos produtos de panificação, parte dos entrevistados se mostraram com receio das informações ali transmitidas. O sujeito B citou: "geralmente a questão do selo verde eu não levo em consideração por achar que é mais marketing do que (o produto) realmente ser verde", o mesmo ainda afirmou que utiliza pesquisas na internet para basear suas decisões de compra, o que pode indicar um aumento do considerado boicote dos consumidores, que utilizam as redes sociais e mídia na internet sem se ater à Responsabilidade Social Corporativa (CRUZ, 2011).

Por meio dos dados obtidos nas entrevistas, pode-se perceber que parte dos sujeitos entrevistados mudaram de opinião em relação à compra de um produto funcional após a verificação da tabela nutricional, passando a levá-lo em consideração como opção de compra (Gráfico 2), mesmo que a verificação da tabela 
nutricional não seja um hábito que costumam praticar quando vão ao mercado. $\mathrm{O}$ sujeito E, por exemplo, quando questionado se normalmente avalia as informações da rotulagem nutricional dos alimentos, citou: "analiso mais o que está escrito na frente e os ingredientes". Apesar de reconhecer que o produto A funcional apresentava características nutricionais mais interessantes em relação às fibras, muitos ainda permaneceram em dúvida entre mais de uma opção dos produtos apresentados.

Gráfico 2 - Percentual de intenção de compra após conhecimento da tabela nutricional de cada produto

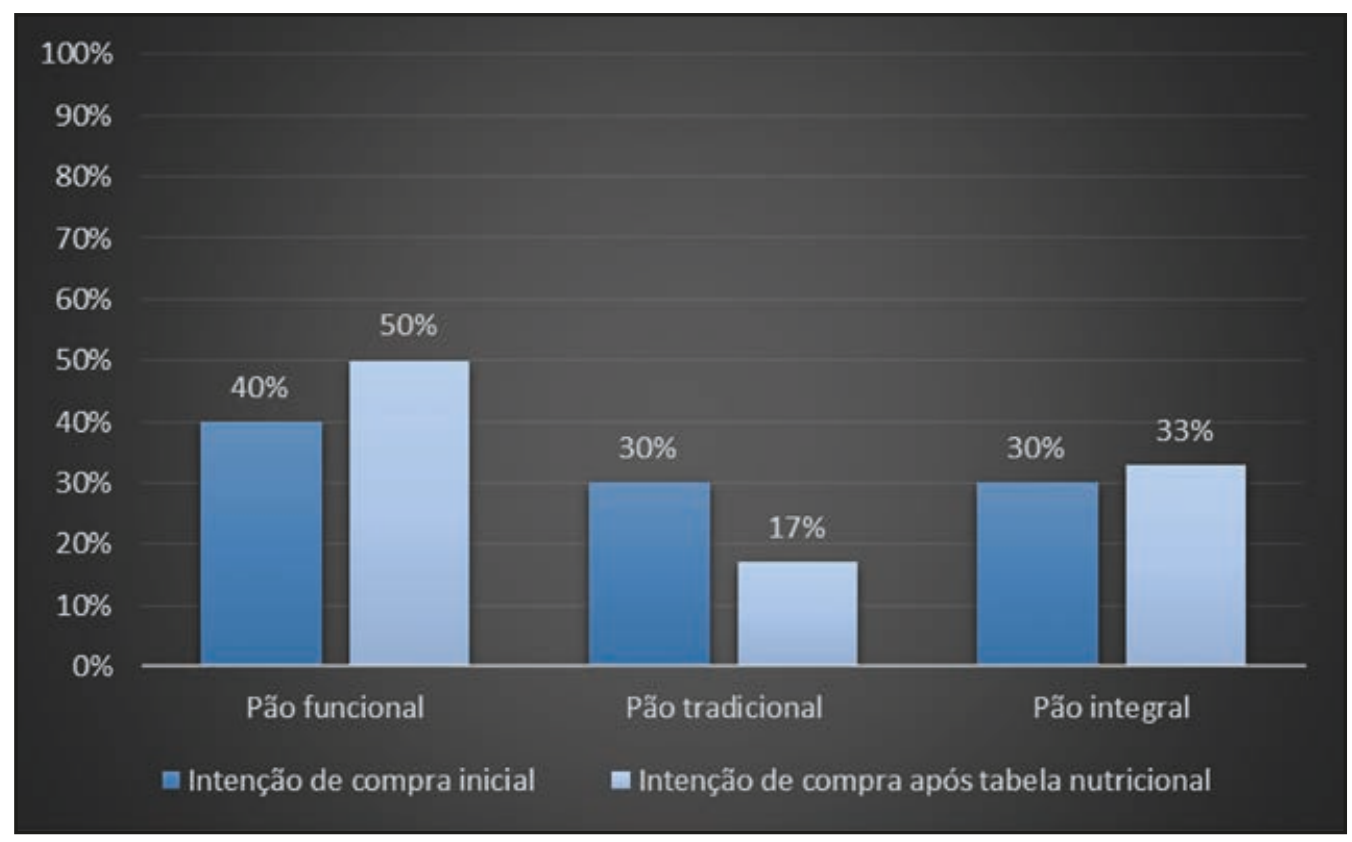

Fonte: Autoria Própria (2017).

Cerca de $80 \%$ dos entrevistados alegaram ter hábitos alimentares saudáveis ou relativamente saudáveis, porém, somente $20 \%$ dos entrevistados mostraram ter conhecimento sobre o que são alimentos funcionais, como se pode verificar no gráfico 3 , e somente $10 \%$ dos entrevistados soube explicar de forma superficial a diferença entre um pão funcional e um pão integral. O sujeito $\mathrm{D}$ chegou a citar que não gosta do termo alimentos funcionais por dar a impressão de que os outros alimentos são disfuncionais, o que mostra que as formas de divulgação desse tipo e alimento, mesmo que crescente nos últimos anos, ainda é muito limitada (RAUD, 2008). 
Gráfico 3 - Conhecimento sobre alimentos funcionais e seu significado

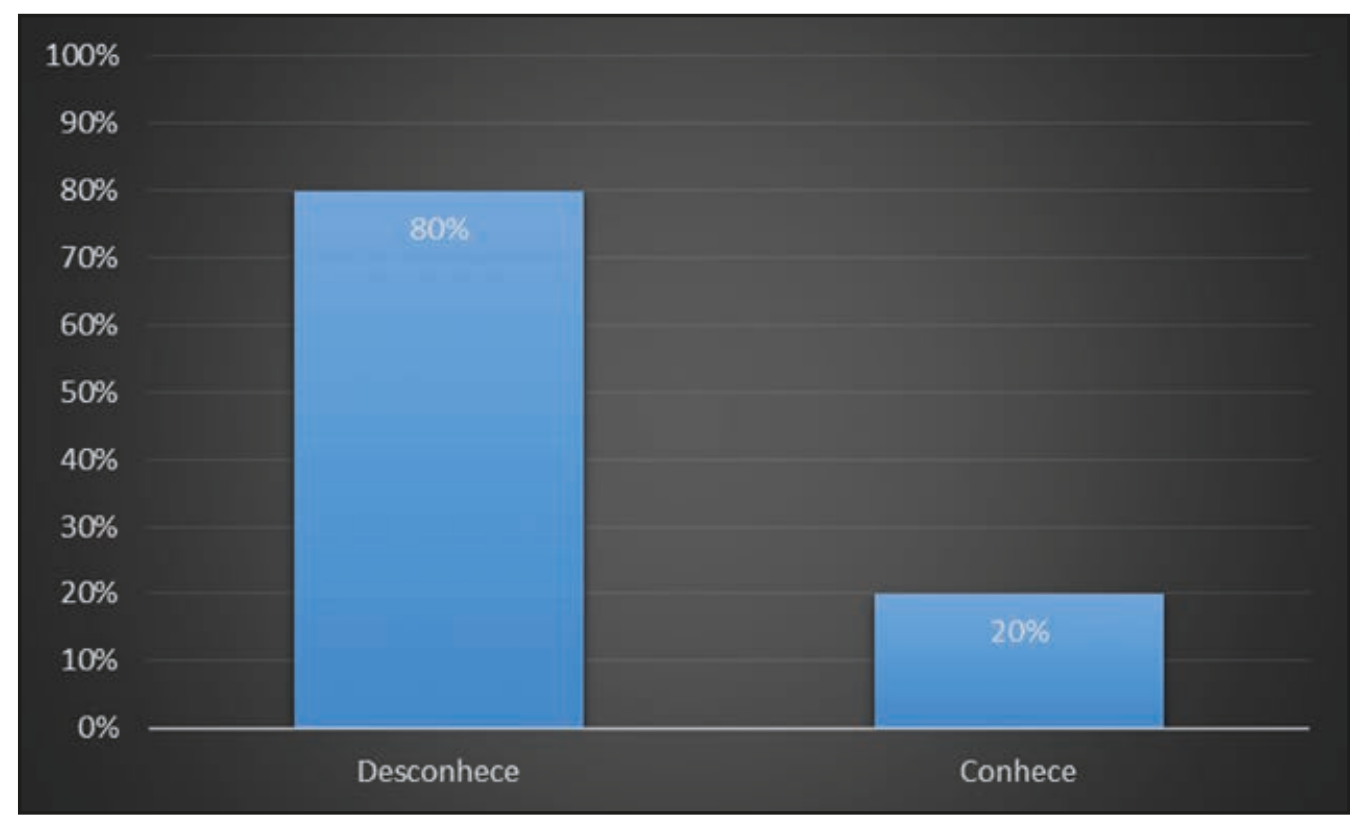

Fonte: Autoria Própria (2017).

Ainda que a maior parte dos entrevistados tenham hábitos alimentares saudáveis, 40\% não costumam praticar exercícios, 40\% deles têm uma vida ativa e praticam exercícios físicos regularmente, e os outros $20 \%$ informaram que não têm uma rotina regular na prática de exercícios (Gráfico 4). Tal resultado aponta que apesar de passados 13 anos da publicação da cartilha da Organização Mundial de Saúde sobre a importância da alimentação saudável e prática de exercícios físicos, a parcela de brasileiros que ainda não praticam essas recomendações pode ser muito grande (WHO, 2004). 
Gráfico 4 - Respostas à pergunta "Você costuma praticar exercícios físicos regularmente e ter uma vida ativa?"

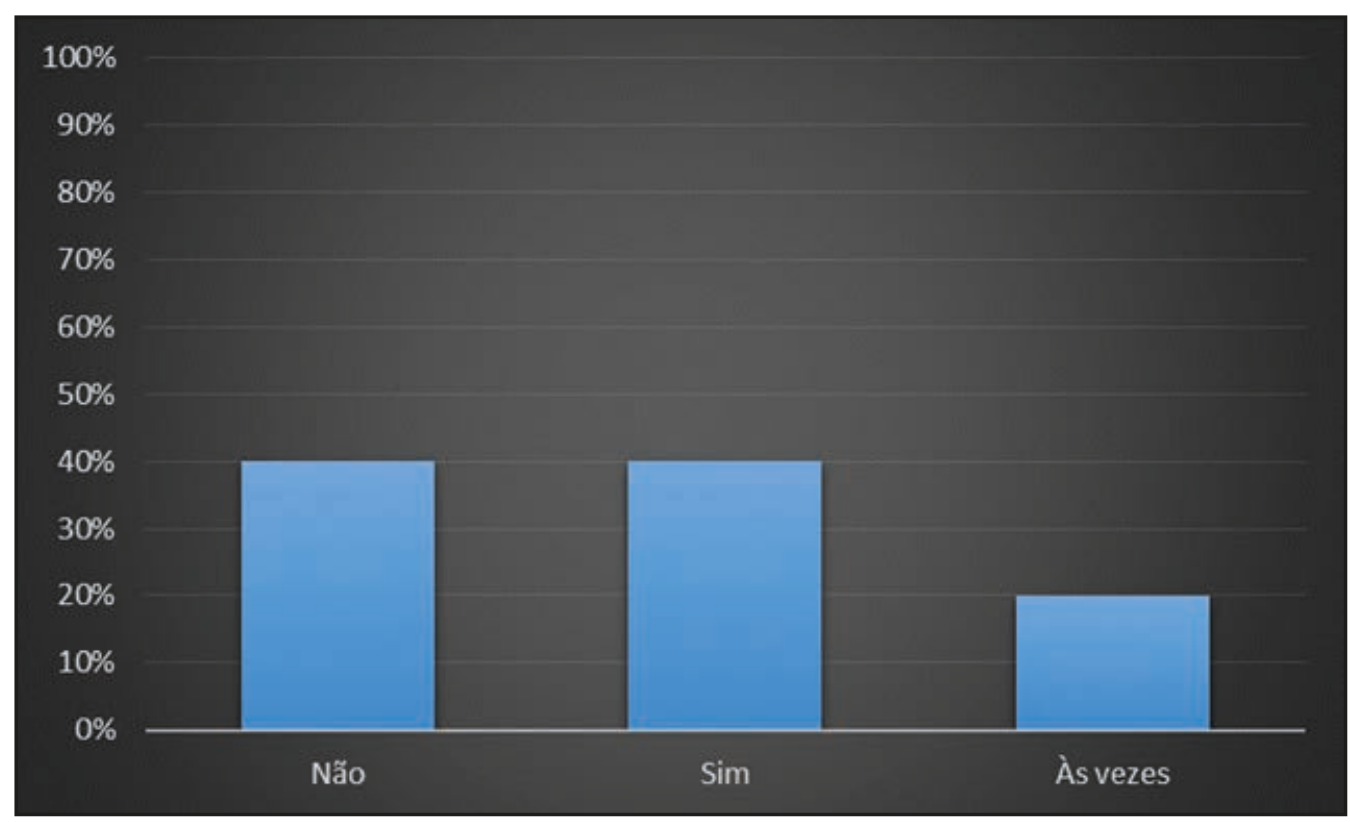

Fonte: Autoria Própria (2017).

O consumo de pães entre os entrevistados foi considerado frequente na maioria dos casos, onde $80 \%$ dos sujeitos da pesquisa afirmaram que consomem pão regularmente e em grande quantidade (Quadro 5). Os dados obtidos mostram que mesmo que o consumo anual de pães no Brasil ainda esteja abaixo dos $60 \mathrm{~kg}$ e $50 \mathrm{~kg}$ per capita recomendado pela Organização Mundial da Saúde (OMS) e a Organização das Nações Unidas (ONU), respectivamente, esse alimento ainda está muito presente na mesa e na escolha alimentar dos brasileiros (PIRES et al., 2009). 
Gráfico 5 - Frequência do consumo de pães

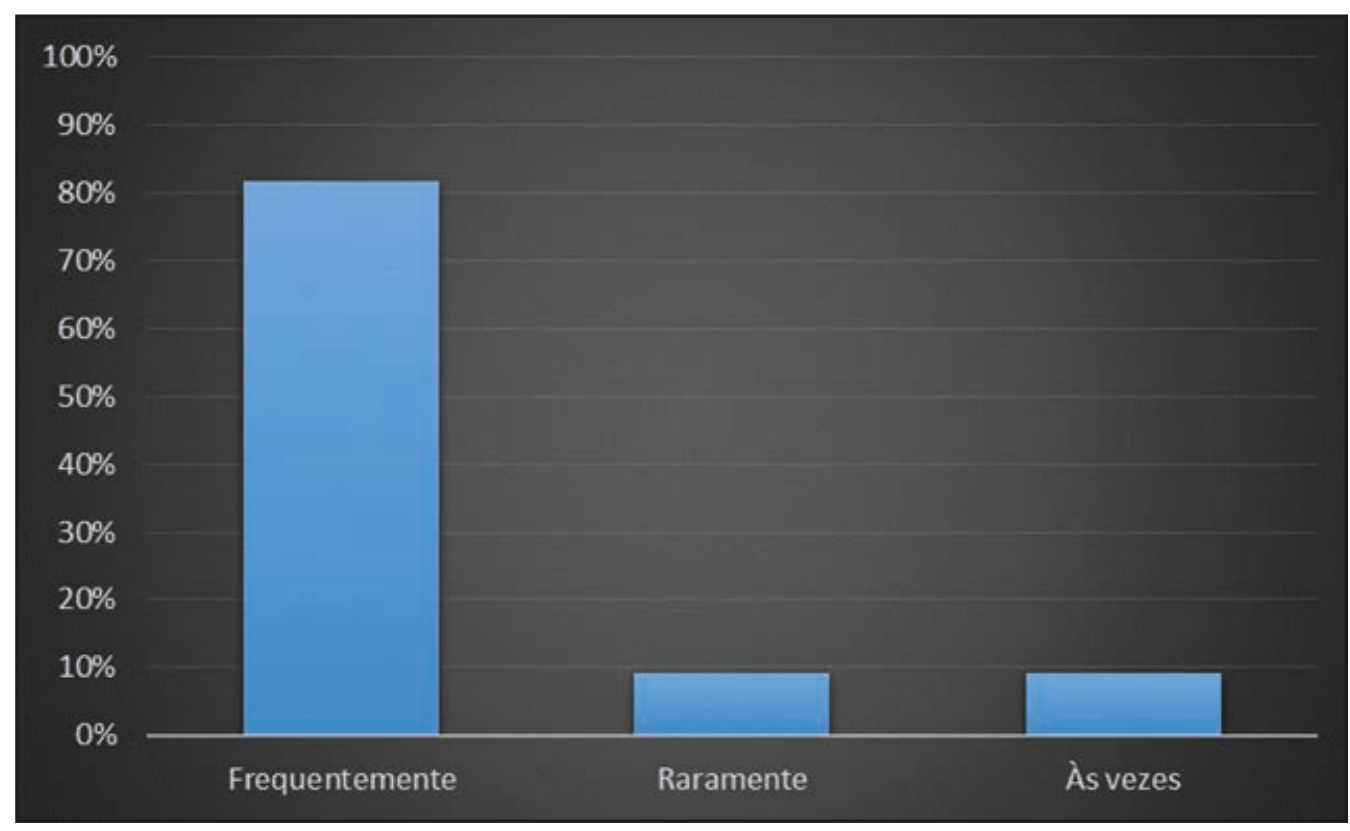

Fonte: Autoria Própria (2017).

Ao sintetizar e comparar as respostas obtidas dos entrevistados com perfil saudável e os com perfil pouco saudável ou não saudável na tabela 2 , pode-se perceber que o público apresentou resultados bem heterogêneos e ao contrário do que era esperado: a escolha de compra do produto A funcional teve maior aderência ao público pouco saudável ou não saudável do que aqueles do grupo principal do estudo. Fator como a leitura das tabelas nutricionais dos alimentos, que é um elemento obrigatório de acordo com a legislação, mostrou-se ser um aspecto pouco relevante para os entrevistados (ANVISA, 2005). Por outro lado, a cor da embalagem surgiu como fator extremamente determinante para a decisão de compra em duas das dez entrevistas realizadas, onde os dois sujeitos pesquisados informaram que não conseguem associar a cor azul com produtos saudáveis e que a cor não lhes agradava; tal reação à cor da embalagem não corresponde a sensação de calma e leveza a que as cores frias (azul, verde, parte do amarelo e roxo) normalmente são associadas (FARINA; PEREZ; BASTOS, 2006). 
Tabela 2 - Comparação dos resultados entre os dois perfis

\begin{tabular}{lccc}
\hline Aspectos analisados & $\begin{array}{c}\text { Perfil } \\
\text { saudável }\end{array}$ & $\begin{array}{c}\text { Perfil não saudável } \\
\text { ou pouco squdável }\end{array}$ & $\begin{array}{c}\text { Porcentagem } \\
\text { Saudável }\end{array}$ \\
\hline $\begin{array}{l}\text { Hábito alimentar } \\
\text { saudável }\end{array}$ & 5 & 5 & $50 \%$ \\
$\begin{array}{l}\text { Prática de exercícios } \\
\text { físicos }\end{array}$ & 4 & 0 & $100 \%$ \\
$\begin{array}{l}\text { Consumo de pão } \\
\text { frequente }\end{array}$ & 3 & 5 & $37,5 \%$ \\
$\begin{array}{l}\text { Procura por produtos } \\
\text { saudáveis }\end{array}$ & 5 & 2 & $71,4 \%$ \\
$\begin{array}{l}\text { Escolha do produto } \\
\text { funcional }\end{array}$ & 3 & 2 & $60 \%$ \\
$\begin{array}{l}\text { Análise da rotulagem } \\
\text { nutricional }\end{array}$ & 2 & 2 & $50 \%$ \\
$\begin{array}{l}\text { Valorização da } \\
\text { embalagem }\end{array}$ & 3 & 3 & $50 \%$ \\
\hline
\end{tabular}

Fonte: Autoria Própria (2017).

Tal falta de associação pode ocorrer por muitas marcas brasileiras utilizarem a cor verde para suas linhas de produtos saudáveis, integrais e com algum apelo nutricional diferenciado dos produtos tradicionais, porém, mesmo que esse dado represente $20 \%$ dos entrevistados neste estudo, para uma pesquisa em maior escala, os resultados podem ser mais conclusivos em relação às emoções e associações despertadas através das cores das embalagens.

$\mathrm{O}$ estudo mostrou que apesar de o nicho estudado ter interesse por seguir bons hábitos alimentares e uma vida saudável, muitas vezes o consumo e compra de produtos denominados saudáveis pelas empresas fica defasado, por conta da falta de informação ou explicação de quais benefícios os produtos podem trazer para seu organismo de uma forma mais simples. Muitos dos entrevistados se mostraram relutantes em adquirir o produto funcional por não conhecerem a linha e qual vantagem ela teria em relação a um produto integral.

Outro aspecto relevante é o fato de o consumidor precisar de conhecimento prévio sobre os tipos de alimentos e suas variedades de classificações antes de chegar ao supermercado. Tal levantamento mostra que, apesar do investimento das empresas no design, cor e qualidade do material da embalagem, há talvez uma falta de investimento na pesquisa de campo em relação à quais informações são necessárias para atrair ou esclarecer as dúvidas do consumidor 
na embalagem e qual o melhor formato de comunicação e estruturação das frases a serem colocadas.

Em relação às embalagens, o estudo demonstra que as empresas utilizam mais a cor verde para a associação com produtos saudáveis, e, quando o consumidor se depara com um alimento funcional rico em fibras, porém com a coloração azul de embalagem, o mesmo prefere o alimento que tenha a embalagem verde por achar que terá mais vantagens e será mais saudável do que a opção em outra cor de embalagem. Isso demonstra mais uma vez a falha em comunicar os reais benefícios do produto por meio da embalagem e diferenciá-los dos outros, de forma que o consumidor saiba qual é o melhor para a sua dieta de acordo com suas necessidades pessoais, e não somente pela cor do pacote.

Com os resultados obtidos não foi possível determinar o quanto os hábitos alimentares saudáveis de um nicho específico de consumidores pode afetar a produção de pães, por conta da dificuldade de compreensão por parte dos consumidores sobre as diferenças dos produtos apresentados, como também pela falta de conhecimento de algumas terminologias em relação aos pães e aos alimentos funcionais. Para que haja um resultado mais preciso, as entrevistas realizadas podem servir como base para o desenvolvimento de um questionário mais objetivo para recolher uma quantidade maior de respostas e para que seja possível analisar estatisticamente o comportamento desse grupo e suas influências nos mais diversos segmentos de alimentos, assim como para compreender as deficiências na comunicação entre o setor de panificação e o consumidor através da embalagem.

\section{CONCLUSÃO}

O presente estudo visou verificar a influência de nichos específicos de consumidores na produção de pães e na forma de divulgação e marketing dos produtos direcionados a esses consumidores, com o intuito de verificar os pontos de melhorias e novas ideias para o setor de panificação.

Observou-se, por meio das entrevistas realizadas, que o entre os entrevistados não há os mesmos princípios de análise dos produtos alimentícios, e que quando se trata dos pães cada um tem um critério pessoal acerca do melhor produto para consumo, que pode ser o preço, a marca, os ingredientes, as informações superficiais da parte frontal da embalagem e até mesmo a cor de embalagem utilizada para os produtos considerados saudáveis

Em relação aos consumidores que não apresentaram perfil saudável, os dados demonstram que esses são mais interessados por tabelas nutricionais dos 
produtos e pelo consumo de alimentos funcionais, os mesmos ainda consideram importante o consumo dos produtos com apelo saudável.

Sendo assim, o estudo mostrou que, para que se obtenha uma análise mais estatística dos resultados, o formato das entrevistas tem de ser mais objetivo, com a perspectiva de enquadrar os entrevistados em uma categoria mais homogênea, para que os dados possam ser utilizados nas áreas de marketing das empresas, visando ao melhoramento e ao desenvolvimento de novos produtos e embalagens.

Como principais limitações deste estudo, podem ser citadas a quantidade de entrevistas realizadas, o curto tempo de algumas entrevistas causado pela falta de conhecimento dos entrevistados em relação aos alimentos funcionais, a dificuldade em quantificar os resultados, por terem sito muito heterogêneos, e em utilizá-los de uma forma mais estatística. Do contrário, seria possível utilizar tais resultados como fonte de sugestões para as empresas que desenvolvem pães com apelo saudáveis, a fim de melhorar sua comunicação com os consumidores por meio das melhorias em suas embalagens e meios de propagação de informações.

Dessa forma, como sugestão para trabalhos futuros, o atual estudo deixa aberta a discussão sobre como as mudanças dos hábitos alimentares e novas necessidades dos consumidores no Brasil tem afetado setores de produção tão tradicionais como o setor da panificação, fazendo com que eles busquem a inovação e readaptação às cada vez mais novas tendências de consumo, de forma que os trabalhos possam apresentar dados mais estatísticos dessas mudanças e auxiliar na melhoria dos diversos setores de produção de alimentos.

\section{REFERÊNCIAS}

ABIP. Associação Brasileira da Indústria de Panificação e Confeitaria. Desempenho do setor de panificação e confeitaria brasileiro. 2012. Disponível em: $<$ http://www.abip.org.br/perfil_internas.aspx?cod=333> Acesso em: 21 set. 2016.

AGÊNCIA NACIONAL DE VIGILÂNCIA SANITÁRIA. ANVISA. Resolução - RE $n^{o} 263$ de 22 de setembro de 2005. Disponível em: <http://portal. anvisa.gov.br/documents/33880/2568070/RDC_263_2005.pdf/d6f557da-7c1a-4bc1-bb84-fddf9cb846c3>. Acesso em: 17 ago. 2017.

. Resolução - RE $n^{\circ} 1.591$ de 14 de junho de 2017. Disponível em: $<$ http://pesquisa.in.gov.br/imprensa/jsp/visualiza/index.jsp?data=16/06/2017\&jornal=1\&pagina $=34 \&$ totalArquivos=72>. Acesso em: 17 ago. 2017 . 
. Rotulagem nutricional obrigatória: manual de orientação aos consumidores. Brasília, DF, 2008. Disponível em: <http://portal.anvisa.gov.br/documents/33916/396679/manual_consumidor.pdf/e31144d3-0207-4a37-9b3b-e4638d48934b>. Acesso em: 18 ago. 2017.

AGROCLUSTER RIBATEJO. Tendência do Mercado Alimentar do Brasil: Aspetos do consumo, produto, distribuição e comunicação. 2015. Disponível em: $<$ https://www.agrocluster.com> Acesso em: 18 ago. 2016.

ANDRADE, M. M. Introdução à metodologia do trabalho científico. São Paulo: Atlas, 2006.

BARBOSA, L. et al. As tendências da alimentação. In: VIALTA, A. et al. Brasil Food Trends 2020. São Paulo: Gráfica Ideal, 2010. p. 23-37.

BATISTA FILHO, M.; RISSIN, A. A transição nutricional no Brasil: tendências regionais e temporais. Cad. Saúde Pública, v. 19, n. 1, 2003.

BORTOLON, B.; MENDES, M. S. S. A importância da educação ambiental para o alcance da sustentabilidade. Revista Eletrônica de Iniciação Científica, Itajaí, v. 5, n. 1, p. 118-136, jan./mar. 2014.

BRAGA, P. Pão da paz: 195 receitas de pão de países da ONU. São Paulo: Gaia, 2006.

COELHO, A. B.; AGUIAR, D. R. D.; FERNANDES, E. A. Padrão de consumo de alimentos no Brasil. RESR, Piracicaba, v. 47, n. 2, p. 335-362, abr. 2009.

COSTA, A. C. P. B.; MACÊDO, F. S.; HOCZAR, G. Fatores que influenciam o consumo de alimentos. In: VIALTA, A. et al. Brasil Food Trends 2020. São Paulo: Gráfica Ideal, 2010. p. 23-37.

CRUZ, B. P. A. Boicote de consumidores em relação à responsabilidade social corporativa. Anais do XXXV EnAnpad. Rio de Janeiro, 2011. 
DIPLOCK A.T. et al. Scientific Concepts of Functional Foods in Europe: Consensus Document. British Journal of Nutrition, v. 88, p. S1-S27, 1999.

EXAME. Brasil é o quarto maior mercado para produtos saudáveis. 2015. Disponível em: $<$ https://exame.com> Acesso em: 8 set. 2016.

FARINA, M.; PEREZ, C.; BASTOS, D. Psicodinâmica das cores em comunicação. Rev. e ampl. São Paulo: Edgard Blucher, 2006.

FELIPPE, F.; SANTOS, A. M. Novas demandas profissionais: obesidade em foco. Revista da ADPPUCRS, v. 5, n. 1, p. 63-70, 2004.

FERREIRA, M. R.; VALDUGA, V.; BAHL, M. Baixa gastronomia: caracterização e aproximações teórico-conceituais. Turismo em Análise, Curitiba, v. 27, n. 1, p. 207-228, abr. 2016.

GOULART, G. S.; CHEUNG, T. L. Alimentos inovadores: comportamentos neofóbicos e desafios para as indústrias do setor. Gestão de Produção, São Carlos, v. 21, n. 3, p. 491-502, set. 2014.

IBOPE. Instituto Brasileiro de Opinião e Estatística. O perfil do consumo de alimentos no Brasil. In: VIALTA, A. et al. Brasil Food Trends 2020. São Paulo: Gráfica Ideal, 2010. p. 49-61.

INSTITUTE OF MEDICINE. Weight Gain During Pregnancy: Reexamining the Guidelines 2009. Disponível em: <www.nap.edu/cata log/12584.html> Acesso em: 11 jun. 2017.

JACOB, H. E. 6000 anos de pão. Lisboa: Antígona, 1944.

KAC, G.; VELÁSQUEZ-MELÉNDEZ, G. A transição nutricional e a epidemiologia da obesidade na América Latina. Cad. Saúde Pública, v. 19, n. 1, 2003.

KOK, F. J. Functional foods: relevance of genetic susceptibility. In: PROCEEDINGS OF FORUM ON FUNCTIONAL FOOD. Anais... Strasbourg: Council of Europe Publishers, 1999. p. 217-229. 
KOTLER, P. Administração de marketing. 3. ed. São Paulo: Atlas, 1993.

. Administração de marketing. 4. ed. São Paulo: Atlas, 1995.

.; ARMSTRONG, G. Princípios de marketing. Pearson Prentice Hall, São Paulo, 2007.

MACHADO, E. R. et. al. Marketing de relacionamento aplicado com ética: excelência no atendimento e satisfação do cliente. 2012. 37 f. Trabalho de Conclusão de Curso (Graduação em Administração) - Faculdade Metodista Granbery, Juiz de Fora, 2012.

NÚCLEO DE ESTUDOS E PESQUISAS EM ALIMENTAÇÃO. NEPA. Tabela brasileira de composição de alimentos - TACO. 4. ed. Campinas: Unicamp, 2011.

PIRES, C. E. R. et al. Estratégias no mercado panificador: a nova tendência delicatessen. Pretexto, Belo Horizonte, v. 10, n. 2, p. 43-58, abr./jun. 2009.

PORTAL BRASIL. Mais da metade dos adultos está acima do peso. Saúde. PNS. 2015. Disponível em: <http://www.brasil.gov.br/saude/2015/08/mais-da-metade-dos-adultos-estao-acima-do-peso> Acesso em: 20 maio 2017.

RAUD, C. Os Alimentos funcionais: a nova fronteira da indústria alimentar análise das estratégias da Danone e da Nestlé no mercado brasileiro de iogurtes. Revista de Sociologia e Política, Universidade Federal do Paraná, Curitiba, Brasil, v. 16, n. 31, p. 85-100, 2008.

SEBRAE. Serviço Brasileiro de Apoio às Micro e Pequenas Empresas. Estudo da atividade padaria - Consultoria de Administração Geral - Unidade Operacional de Orientação Empresarial SEBRAE. São Paulo, fev. 2000.

SEBRAE/ABIP. Serviço Brasileiro de Apoio às Micro e Pequenas Empresas/ Associação Brasileira da Indústria de Panificação e Confeitaria. Estudo de tendências: perspectivas para a panificação e confeitaria. 2009. Disponível: $<$ https:// www.abip.org.br> Acesso em: 20 set. 2016. 
SOCIEDADE BRASILEIRA DE ALIMENTOS FUNCIONAIS. 2017. Disponível em: <http:// www.sbaf.org.br>. Acesso em: 21 ago. 2017.

SOUZA, A. M. et al. Alimentos mais consumidos no Brasil: Inquérito Nacional de Alimentação 2008-2009. Revista de Saúde Pública, São Paulo, v. 47, n. 1, p. 190-199, fev. 2013.

SOUZA, L. J. et al. Prevalência de obesidade e fatores de risco cardiovascular em Campos, Rio de Janeiro. Arq. Bras. Endocrinol. Metab., v. 47, n. 6, p. 669676, 2003.

WORLD HEALTH ORGANIZATION (WHO). Global Strategy on Diet, Physical Activity and Health. World Health Assembly WHA 57, 22 May 2004. Disponível em: <www.who.int> Acesso em: 10 ago. 2017.

. Obesity: Preventing and Managing the Global Epidemic. Genebra: WHO, 2000. (Technical Report Series, 894). 
